\title{
Hematocrit Changes as Parameters for Giving Mannitol in Severe Head Injury
}

\author{
Donny Valensius Susanto ${ }^{1}$, Trijoso Permono ${ }^{1 *}$ \\ ${ }^{1}$ Department of Surgery, Faculty of Medicine, Universitas Sriwijaya, Indonesia \\ *Correspondence Author Email : trijosopermono@gmail.com
}

\begin{abstract}
Introduction. Incidence of head injuries is also quite high in Indonesia, around 1.4 million cases per year with a mortality rate of $15-20 \%$ in the population aged 5 to 35 years. Head injuries are commonly divided into two separate time periods namely primary and secondary brain injuries. Primary brain injury is physical damage to the parenchyma (tissue and blood vessels) that occurs during a traumatic event, thus causing compression of the surrounding brain tissue. Secondary brain injury is a continuation of the results of primary brain injury with the main complications of brain injury in the following hours and days. This study was aimed to asses the benefits of administration of mannitol in cases of severe head injury in South Sumatra, Indonesia.

Methods. This research was a clinical trial without comparison by looking at hematocrit levels in patients with severe head injuries with intracranial hypertension before and after given mannitol therapy. Data analysis was performed with IBM SPSS Version 23. Data was presented in the form of narrative tables. Then the paired $\mathrm{T}$ test was performed. $\mathrm{P}$ value $<0.05$.

Results. From 39 research subjects, the age of the subjects ranged between 6-88 years with an average of 33 years. Based on sex there were 28 male sufferers (71.8\%) and there were 11 female sufferers $28.2 \%$. GCS varies from 3 to GCS 8 intra-cranial abnormalities. From 39 research subjects with severe head injury without surgery, a hematocrit examination was performed before, after 10 minutes and 6 hours of injection of mannitol bolus $1 \mathrm{~g} / \mathrm{kg}$ body weight. It was obtained
\end{abstract}




\section{STS SRIWIJAYAJOURNAB OFSURGERY}

that averaged hematocrit before mannitol administration was 34, after 10 minutes was 33 and after 6 hours was 35 .

Conclusion. There is a decrease in hematocrit levels after administration of bolus mannitol $1 \mathrm{~g} /$ $\mathrm{kg} \mathrm{BW}$ at the beginning of mannitol administration and hematocrit will increase again after 6 hours of mannitol administration

\section{Keywords: hematocrit, severe head injury, mannitol, parameter change}

\section{Introduction}

Head injury is a global problem that causes death, disability and mental deficits. In 2010 , according to the Center for Disease Control and Prevention, there were 2.5 million head injury incidents in the United States, where data were obtained from the number of patient visits in the emergency department ${ }^{1}$. In Indonesia the incidence of head injuries is also quite high, around 1.4 million cases per year with a mortality rate of $15-20 \%$ in the population aged 5 to 35 years. ${ }^{2}$ Head injury case itself is a case that is very often found in Mohammad Hoesin general hospital, recorded 77 cases of head injuries received through the emergency department in June 2017 at Mohammad Hoesin general hospital Palembang.

Head injuries are commonly divided into two separate time periods namely primary and secondary brain injuries. Primary brain injury is physical damage to the parenchyma (tissue and blood vessels) that occurs during a traumatic event, thus causing compression of the surrounding brain tissue. Secondary brain injury is a continuation of the results of primary brain injury with the main complications of brain injury in the following hours and days. Many complications of secondary brain injury, which can aggravate brain trauma and result in secondary brain injury, 


\section{SSS SRIWIJAYAJOURNABOPSURGERY}

namely intracranial disorders include cerebral edema, hematoma, hydrocephalus, intracranial hypertension, vasospasm, metabolic disorders, excitotoxicity, calcium ion toxicity, infection, and seizures. ${ }^{1,2}$ Primary brain injury and secondary brain injury cause increased vascular permeability, cerebral edema, and increased intracranial pressure, all three of which are determinants of the prognosis of a patient with severe head injury. Cerebral edema can be classified as cytotoxic or vasogenic cerebral edema. Cytotoxic edema is swelling of cells arising from injury, generally in the form of ischemic or toxic injury. Vasogenic edema is extracellular edema that arises secondary to capillary damage, and can cause blood-brain barrier damage. Cytotoxic edema occurs a few minutes to several hours after injury occurs, whereas vasogenic edema occurs several hours to several days after the onset of injury. The type of edema that arises is important to know in determining therapy, because cytotoxic edema is more resistant to therapy.

Mannitol has been widely recognized as the main therapy in the treatment of intracranial hypertension, but hypertonic saline solution is an alternative therapy that is also potential for the treatment of intracranial hypertension. morbidity. One key therapy for head injuries with cerebral edema and accompanied by increased Intracranial Pressure (ICP) is the administration of hyperosmolar therapy. Hyperosmolar solution which is often used for the treatment of intracranial hypertension is mannitol 20\%. ${ }^{3}$ Mannitol has been used by medical surgery since 1960 , ranging from 3 decades to the present. Mannitol is effective in treating intracranial hypertension at a dose of $0.25-1 \mathrm{~g} / \mathrm{kg} \mathrm{BW}$ given intravenously by bolus, and works within 10-15 minutes. ${ }^{3}$

Many hypotheses explain the decrease in ICP due to mannitol, one of which is cerebral hemodynamic changes due to mannitol. The main effect of mannitol is reducing blood viscosity which will increase cerebral blood flow and increase brain oxygenation. ${ }^{2}$ Viscosity of blood is 


\section{STS SRIWIJAYA JOURNAB OFEURGERY}

strongly influenced by blood hematocrit levels. Studies have shown that brain blood flow will drop significantly in the first few hours after severe head injury in both human and animal models. Hematocrit blood between 30 - 35\% is widely accepted as the optimal level in patients with head injuries. This figure was obtained from several experimental studies of blood viscosity and oxygen transport capacity. ${ }^{4-9}$ A study conducted a retrospective record review of patients with severe head injuries. The final results measured were the Glasgow coma scale (GCS), the Glasgow output score (GOS), and the Ranchos Los Amigos score (RLA) at the time of hospital discharge (D/C). As a result, univariant analysis showed the lowest hematocrit levels $(<30 \%)$ associated with decreased D/C GCS scores, D/C GOS, and RLA. Linear regression showed, with a hematocrit <30\% associated with an increase in neurological status as measured by GCS $(\mathrm{p}=0.001)$, GOS $(\mathrm{p}=$ 0.001), and RLA $(\mathrm{p}=0.001) .{ }^{10-14}$ Hematocrit levels $30-35 \%$ are levels optimal hematocrit to get a good outcome after head injury. This figure was obtained from the results of experimental tests of blood viscosity with oxygen carrying capacity. ${ }^{15-20}$ This study was the first research in assessing the benefits of hematocrit levels as a marker for administration of mannitol in cases of severe head injury in the Malay population in South Sumatra, Indonesia.

\section{Methods}

This research was a clinical trial without comparison by looking at hematocrit levels in patients with severe head injuries with intracranial hypertension before and after given mannitol therapy. Research subjects (39 people) were severe head injury patients who would receive mannitol therapy at Mohammad Hoesin general hospital Palembang. The inclusion criteria were patients with severe head injuries who performed CT scans of all sexes, patients with severe head injuries with GCS 3 to 8, patients of any age with traumatic brain injury, there were signs of intra- 


\section{STS SRIWIJAYA JOURNABOFEURGERY}

cranial hypertension, patients would receive mannitol therapy. Exclusion criteria were patients with severe brain injury accompanied by other severe accompanying injuries (multiple trauma), severe head injury patients without intra-cranial hypertension, patients with blood disorders, patients with anemia, patients who had received drugs that affected blood viscosity.

Research subjects who met the inclusion criteria were subsequently performed CT scans, to assess the type of trauma from head injury. Then, hematocrit examination was done, mannitol were administered as much as $1 \mathrm{mg} / \mathrm{kg} \mathrm{BW}$. After 10 minutes the measurement of hematocrit levels was repeated. After 6 hours, re-examination of hematocrit levels was conducted.

Data analysis was performed with IBM SPSS Version 23. Data was presented in the form of narrative tables. Then the paired $\mathrm{T}$ test was performed. $\mathrm{P}$ value $<0.05$.

\section{Results}

From 39 subjects, the age of the subjects ranged between 6-88 years with an average of 33 years. Age groups based on the age of children and adults, namely the age group <14 years by 9 subjects $(23.1 \%)$ and $>14$ years by 30 subjects (76.9\%). Severe head injuries patients without operative measures based on sex there were 28 males $(71.8 \%)$ and there were 11 females $28.2 \%$. Patients with severe head injuries without operative measures based on the GCS scale were in averaged GCS 7, the lowest GCS 3 and the highest GCS 8. Patients with severe head injuries without operative action found various kinds of intra-cranial abnormalities, most of which were cerebral edema.

Table 1. Baseline Characteristics Research Subjects

\begin{tabular}{lll}
\hline Variable & Amount & Percentage (\%)
\end{tabular}




\section{SSS SRIWIJAYA JOURNAB OP SURGERУ}

\section{Sex}

Male

28

71,8

Female

11

28,2

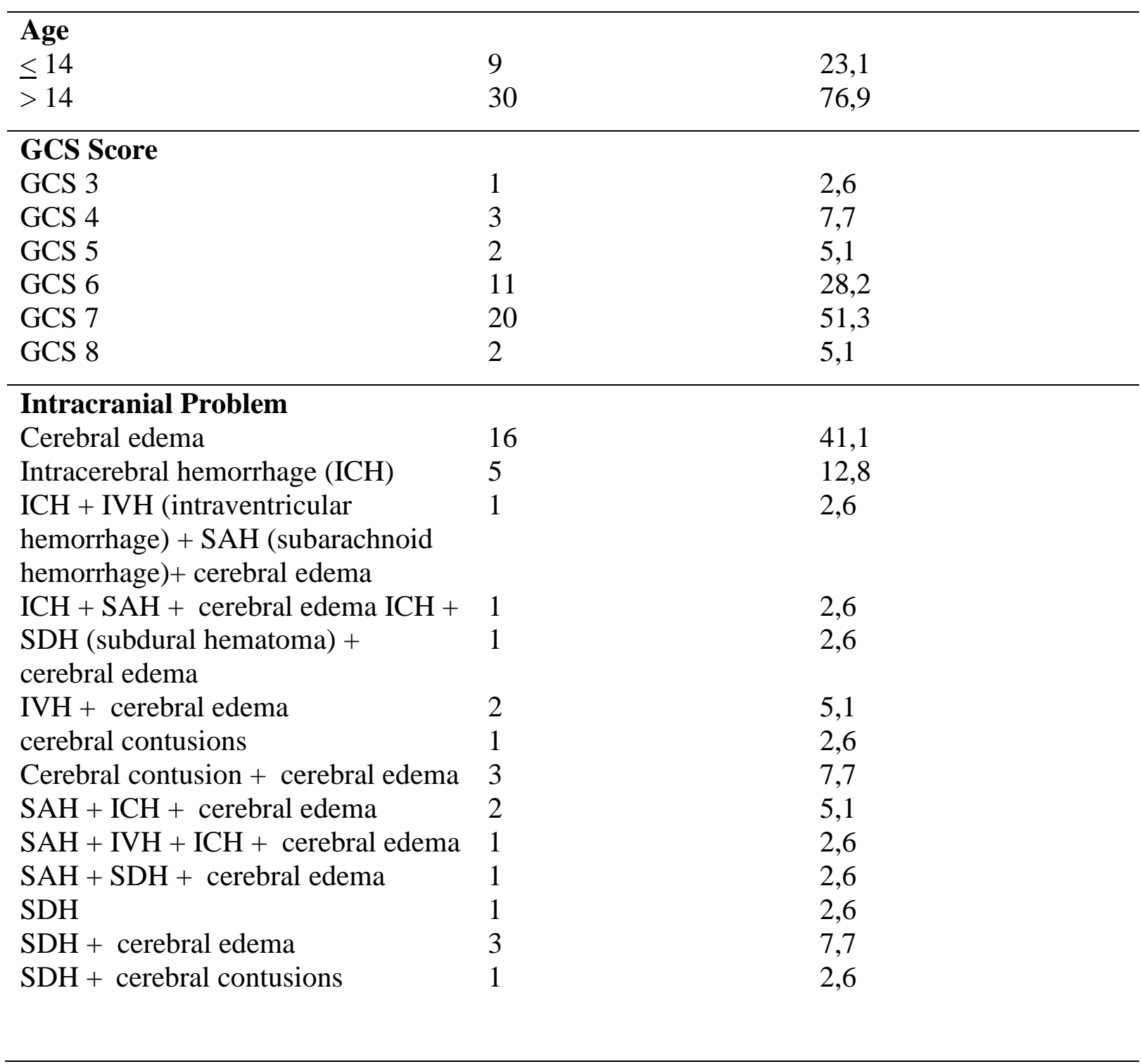

There was a significant difference in the average number of hematocrit before administering bolus mannitol $1 \mathrm{~g} / \mathrm{kg} \mathrm{BW}(34.85 \pm 6.827)$ compared to hematocrit levels 10 minutes after administering mannitol $(33.03 \pm 6,551)$. There was no significant difference in the average number 


\section{SIS SRIWIJAYAJOURNABOFEURGERY}

of hematocrit before the bolus mannitol $1 \mathrm{~g} / \mathrm{kgBW}(34.85 \pm 6.827)$ compared to hematocrit levels 6 hours after mannitol administration $(35.44 \pm 7.426)$.

Table 2. Mannitol Effects on Hematocrit Level

\begin{tabular}{l|c|c|c|c}
\hline \multirow{2}{*}{ Variable } & \multicolumn{2}{|c|}{ Administration of Mannitol 1 mg /Kg BW } & P value \\
\cline { 2 - 5 } & Before & After 10 minutes & after 6 Hours & \\
\hline Hematocrit & $34,85 \pm 6,827$ & $33,03 \pm 6,551$ & $35,44 \pm 7,426$ & $\begin{array}{r}\mathrm{P}=0,00^{*} \\
\mathrm{P}=0,42^{* *}\end{array}$ \\
\hline
\end{tabular}

Note :

* = Paired T Test Hematocrit; before vs after 10 minutes administration, $\mathrm{p}<0,05$;

$* *=$ Paired $\mathrm{T}$ test hematocrit; before vs after 6 hours administration.

\section{Discussion}

From 39 research subjects, the age of the subjects ranged between 6-88 years with an average of 33 years. Age groups based on the age of children and adults, namely the age group $<14$ years by 9 subjects $(23.1 \%)$ and $>14$ years by 30 subjects $(76.9 \%)$. Based on sex there were 28 male sufferers $(71.8 \%)$ and there were 11 female sufferers $28.2 \%$. GCS varies from 3 to GCS 8 intra-cranial abnormalities, most of which are cerebral edema. From 39 research subjects with severe head injury without surgery, a hematocrit examination was performed before, after 10 


\section{SSS SRIWIJAYAJOURNABOPSURGERY}

minutes and 6 hours of injection of Manitol bolus $1 \mathrm{~g} / \mathrm{kg}$ body weight. It was obtained that averaged hematocrit before mannitol administration was 34, after 10 minutes was 33 and after 6 hours was 35 .

Statistical test results using paired t-test obtained $\mathrm{p}$ value $=0.008$ with a value of $\alpha=0.05$ $(p<\alpha)$. This result shows that there is a significant difference in the average number of hematocrit before performing bolus mannitol $1 \mathrm{~g} / \mathrm{kg}$ body weight compared to hematocrit levels 10 minutes after administering mannitol. The effect of mannitol in reducing blood viscosity is obtained by decreasing hematocrit, hematocrit decreases dramatically 10 minutes after administration of mannitol, and remains low for the next 30 minutes. ${ }^{21-23}$.

There was no significant difference in the average number of hematocrit before the bolus mannitol $1 \mathrm{~g} / \mathrm{kg} \mathrm{BW}$ compared with hematocrit levels 6 hours after mannitol administration $(\mathrm{P}=$ 0.42). There was a significant difference in the average number of hematocrit after a bolus of mannitol $1 \mathrm{~g} / \mathrm{kgBW}$ compared to a hematocrit level of 10 minutes (mean: $33.03 \pm 6.551$ ) compared to hematocrit levels after 6 hours of mannitol administration (mean: $35.44 \pm 7.426$ ). This shows that the initial administration of mannitol can reduce hematocrit levels, thereby reducing blood viscosity which can increase oxygen transport to the brain. ${ }^{24-26}$

\section{Conclusion}

There is a decrease in hematocrit levels after administration of bolus mannitol $1 \mathrm{~g} / \mathrm{kg} \mathrm{BW}$ at the beginning of mannitol administration and hematocrit will increase again after 6 hours of mannitol administration.

\section{References}




\section{STS SRIWIJAYA JOURNAB OFEURGERY}

1. Bullock MR, Povlishock JT. Guidelines for the management of severe traumatic brain injury. Edisi ke-3. Journal of Neurotrauma. 2007;24(1): S1-S2.

2. Bisri DY, Manitol Untuk Hipertensi Intrakranial Pada Cedera Otak Traumatik ; Apakah Masih Diperlukan ?, Jurnal Neuroanastesia Indonesia, JNI 2013, 177-87

3. Haddad S, Arabi Y. Critical care management of severe traumatic brain injury in adults. Scandinavian Journal of Trauma, Resuscitation and Emergency Medicine 2012, 20:12.

4. Deutsch H, Ullman JS. What is the optimal Hematocrite and Hemoglobin for Head Injury Patients ?, in Brain Injury, Chapter 15, p88-90.

5. Langlous, Brown R, The Journal of Head Trauma Rehabilitation,2006 November, volume 21. p 544-548.

6. Silver MJ, Callister TW, Textbook of Traumatic Brain Injury, $2^{\text {nd }}$ ed, p415-26.

7. Langlous BL. The epidemiology and impact of traumatic brain injury : a brief overview. The Journal of Head Trauma Rehabilitation.2006. vol 21.p 544-548.

8. Dewanto G. Suwono WJ. Riyanto B, Turana Y, Diagnosis dan Tatalaksana Penyakit Saraf, Jakarta: ECG. 2009

9. Japardi I. Cedera kepala. PT Bhuanailmu popular. 2004. p34-49

10. Mata FB, David K. Textbook of Neuroanesthesia and Critical Care. Greenwich Medical media LTD. 2000, p51-99

11. Smith, Neuropathology. Textbook of Traumatic Brain Injury. 2011.2 ${ }^{\text {nd }}$ edition. Chapter 2. p102-32.

12. Bassil F, David K, Turner J. Textbook of Neuroanesthesia and Critical Care.Greenwich medical media LTD.2000

13. Smith, M. Monitoring Intracranial Pressure in Traumatic Brain Injury. International Anesthesia research Society, Volume 106, 2008. No.1:240-248. 


\section{STS SRIWIJAYAJOURNAB OFEURGERY}

14. Padayachy, L., Figaji, A.A., Bullock, M.R. 2010. Intracranial pressure monitoring for traumatic brain injury in the modern era. Childs Nerv Syst, 26:441-452

15. Abdul Rahman I, et al , Terapi Hiperosmolar Pada Cedera Otak Traumatika. Jurnal Neuroanestesia Indonesia, , JNI 2015, 119, 33

16. Klabunde RE. Hemodynamics (Pressure, Flow, and Resistance), Viscosity of Blood. Cardiovascular Physiology Concepts, a text book published by Lippincott Williams \& Wilkins, 2005.

17. Wakai A, McCabe A, Robert I, Schierhout G. Mannitol for acute traumatic brain injury. The Cochrane Collaboration. 2013; 8: 1-21.

18. Wani AA, Ramzan AU, Nizami F, Malik NK, Kirmani AR, Bhatt AR, et al. Controversy in use of mannitol in head injury. Indian Journal of Neurotrauma. 2008; 5(11): 11-3.

19. Irawati.Viskositas Darah dan Aspek Medisnya. Majalah Kedokteran Andalas No.2. Vol.34. Juli-Desember 2010, p102-110.

20. Sharma G, Setlur R, Swamy MN. Evaluation of mannitol as an osmotherapeutic agent in traumatic brain injuries by measuring serum osmolality. MJAFI 2011;67:230-233.

21. Guyton AC, Hall JE. Buku Ajar Fisiologi Kedokteran. Editor bahasa Indonesia: Irawati Setiawan. $9^{\text {th }}$ Ed. Jakarta: EGC,1997.

22. Inao S, Effect of Manitol on Intracranial Pressure-Volume Status and Cerebral Haemodinamik in Brain Edema, Brain Edema VII Proceeding of the $8^{\text {th }}$ Symposium, 1990.

23. Bertram G Katzung,: Diuretic Agent Basic and Clinical Pharmacology, $9^{\text {Th }}$ edition,. Prentice Hall. 2004 hal 263-264 


\section{SSS SRIWIJAYAJOURNABOFEURGERY}

24. Javouhey E, Guerin AC, Chiron M, Incidence and risk factor of severe traumatic brain injury resulting from road accident; a population based study, Pubmed , 2006 Mar, 38 (2): 225-33

25. Faul M, Xu L, Wald MM, Coronado VG. Traumatic brain injury in the United States: emergency department visits, hospitalizations, and deaths. Atlanta (GA): Centers for Disease Control and Prevention, National Center for Injury Prevention and Control; 2010

26. Cold GE, Jull N, Monitoring of cerebral and spinal haemodynamic during neurosurgery. Springer, Denmark 2008. p30. 